\title{
Aboveground Biomass Dynamics in the Low-Mountain Dry Grasslands of the Tianshan Mountains
}

\author{
Xiaotao Huang ${ }^{1,2}$, Geping Luo ${ }^{2,3, ~}$, Hao Wang ${ }^{2,3}$, Jean Baptiste Nsengiyumva ${ }^{2,3}$ \\ ${ }^{1}$ Key Laboratory of Restoration Ecology for Cold Regions in Qinghai, Northwest Institute of Plateau Biology, Chinese Academy of Sciences, \\ Xining, China \\ ${ }^{2}$ University of the Chinese Academy of Sciences, Beijing, China \\ ${ }^{3}$ State Key Laboratory of Desert and Oasis Ecology, Xinjiang Institute of Ecology and Geography, Chinese Academy of Sciences, Urumqi, \\ China
}

\author{
Email address: \\ xthuang@nwipb.cas.cn (Geping Luo) \\ ${ }^{*}$ Corresponding author
}

\section{To cite this article:}

Xiaotao Huang, Geping Luo, Hao Wang, Jean Baptiste Nsengiyumva. Aboveground Biomass Dynamics in the Low-Mountain Dry Grasslands of the Tianshan Mountains. International Journal of Environmental Monitoring and Analysis. Vol. 7, No. 1, 2019, pp. 22-26. doi: $10.11648 /$ j.ijema.20190701.13

Received: March 19, 2019; Accepted: May 5, 2019; Published: May 23, 2019

\begin{abstract}
Identifying the dynamics of aboveground biomass (AB) is vital for effective grassland management, yet knowledge on this phenomenon remains limited in the low-mountain dry grasslands (LMDG) of the Tianshan Mountains. In this study, systematic observations were conducted from 2014 to 2017 to determine AB dynamics in the LMDG of the Tianshan Mountains. To accomplish this, a cutting experiment, an HL20 Bowen ratio system, and TDR300 and WatchDog1400 systems were used. $\mathrm{AB}$ dynamics had unique characteristics, because of the influence of the unique environment of this region. $\mathrm{AB}$ increased rapidly in spring (April - May), and then increased slowly in summer (June - August) and autumn (September - October). Plants entered dormancy in summer (primarily August). In autumn, plants continued to grow after dormancy, except in years with low precipitation which limited plant growth. Plants generally suffered from water stress in this region. However, in spring, the limiting factor for plant growth was heat, not water. Heat might also be the limiting factor for plant growth in autumn. The results are expected to enhance the understanding of AB dynamics in the LMDG of the Tianshan Mountains, providing data to support local grassland management.
\end{abstract}

Keywords: Aboveground Biomass, Low-Mountain Dry Grassland, Water Stress, Soil Volumetric Water Content

\section{Introduction}

Grassland ecosystems are widespread on earth, particularly in arid and semi-arid areas [1]. These areas are vital for livestock production and ecological balances [1]. Biomass is the material basis of ecosystem construction, in addition to being an important indicator of the extent to which ecosystems capture energy and fix carbon dioxide [2]. Furthermore, grassland biomass is highly sensitive to temperature and precipitation [3]. In turn, livestock production is largely arranged in accordance with grassland biomass [4]. Therefore, identifying the dynamics of grassland biomass is vital for maintaining ecological and economic functions when managing grasslands, particularly in arid and semi-arid areas
[5]. As a result, this issue has been receiving increasing levels of research focus [6].

The Tianshan Mountains are an important region for animal husbandry, and low-mountain dry grasslands (LMDG) are widely distributed in this area [7]. Because of the influence of the arid climate, these grasslands are ecologically fragile. Consequently, plants in this region have unique physiological and ecological characteristics [8]. Identifying the dynamics of aboveground biomass $(\mathrm{AB})$ is vital to improve the local environment, and to inculcate sustainable use of local grasslands. It is commonly believed that the limiting factor for plant growth is water, not heat, in this region [4]. Some studies on AB have been conducted in this region using models and remote sensing methods. 
However, these studies focused on estimating the total values of annual $A B$, rather than detailing $A B$ dynamics at different growing stages $[4,6]$. In addition, direct records of biomass from field observations remain limited in this region. Furthermore, direct observations of $\mathrm{AB}$ dynamics during the growing season are also lacking, even though such data are essential for improving the understanding of $\mathrm{AB}$ dynamics in this region.

Compared with other methods, such as models and remote sensing, experimental observations represent the most accurate methodological approach, as real and reliable data are obtained [9]. From 2014 to 2017, a cutting experiment was used to obtain AB data, an HL20 Bowen ratio system to obtain daily meteorological data, and TDR300 and WatchDog1400 systems to obtain soil volumetric water content (SVWC) data in the LMDG of the Tianshan Mountains. Using these directly recorded data, the study aimed to analyse $\mathrm{AB}$ dynamics at different stages of the growing season in the LMDG of the Tianshan Mountains. The results are expected to provide baseline data that can contribute to improving the important grasslands of this region for livestock grazing.

\section{Materials and Methods}

The experimental site $\left(44^{\circ} 05^{\prime} \mathrm{N}, 88^{\circ} 01^{\prime} \mathrm{E}\right.$, elevation $898 \mathrm{~m}$ a.s.1.) is representative of the LMDG region in the Tianshan Mountains, and is located in Fukang, Xinjiang, China. Because of the arid climate, plants suffer water stress in this region $[4,10]$. Precipitation is the only source of water, and is subject to considerable inter-annual variation [10]. The temperature in summer (June - August) is high and was approximately $18.23^{\circ} \mathrm{C}$ from 2014 to 2017 . The temperature rises quickly in spring (April - May) and drops quickly in autumn (September - October). The terrain is flat within a 300 $\mathrm{m}$ radius of the study site, and plant growth is uniform. Gramineae is the main vegetation type. The growing season normally starts at the beginning of April and ends at the beginning of October.

In 2012, a $100 \mathrm{~m} \times 100 \mathrm{~m}$ enclosure was set up at the experimental site, and an HL20 Bowen ratio system was installed inside the enclosure. Thus, daily temperature and precipitation records were obtained. In addition, SVWC data were collected using TDR300 and WatchDog1400 systems. From 2014 to 2017 , twenty groups of $1 \mathrm{~m} \times 1 \mathrm{~m}$ plots were set inside the $100 \mathrm{~m} \times 100 \mathrm{~m}$ fenced area to record AB. Each group included four plots: plot \#1, plot \#2, plot \#3, and plot \#4. Plant growth was uniform in these plots. Plot \#1, plot \#2, plot \#3, and plot \#4 were selected to record AB in 2014, 2015, 2016, and 2017, when plants were cut in each plot, respectively. To observe $\mathrm{AB}$ during the different stages of the growing season, cutting experiments in group \#1-4, \#5-8, \#9-12, \#13-16 and \#17-20 were conducted on 15 May, 6 June, 10 July, 10 August, and 3 October, respectively. The plants in each $1 \mathrm{~m}^{2}$ sampling plot were cut from the ground. The litter was also collected. Then, both components were transferred to the laboratory. $\mathrm{AB}$ was determined by oven-drying the plant material at $65^{\circ} \mathrm{C}$ for $24 \mathrm{~h}$. $\mathrm{AB}$ at the end of certain stage minus $\mathrm{AB}$ at the beginning of certain stage equals $\mathrm{AB}$ during certain stage. To avoid inaccurate results caused by the litter of the previous year, we cleared the litter in the selected plots before the growing season of each year.

\section{Results and Discussion}

Plants grew rapidly in spring, due to the high SVWC caused by snow melt water. As the soil water evaporated, SVWC decreased sharply in summer and autumn [10]. In addition to phenology, low SVWC was the most important factor that led to low $\mathrm{AB}$ in this region [11]. In summer, plants enter dormancy, due to high air temperature and low SVWC (Table 1 and Figures 1 and 2) [12]. Based on the observations, dormancy generally occurred when the $0-40 \mathrm{~cm}$ SVWC was below $15 \%$ in summer, which mainly occurred in August (Figure 1a and Table 1). In 2014 and 2015, plants continued to grow after dormancy, indicating plant growth might occur twice in this region, in some years. These phenomena differed strikingly from those of humid grasslands, indicating that the characteristics of $\mathrm{AB}$ dynamics were unique, due to the influence of the unique environment in the LMDG of the Tianshan Mountains [13].
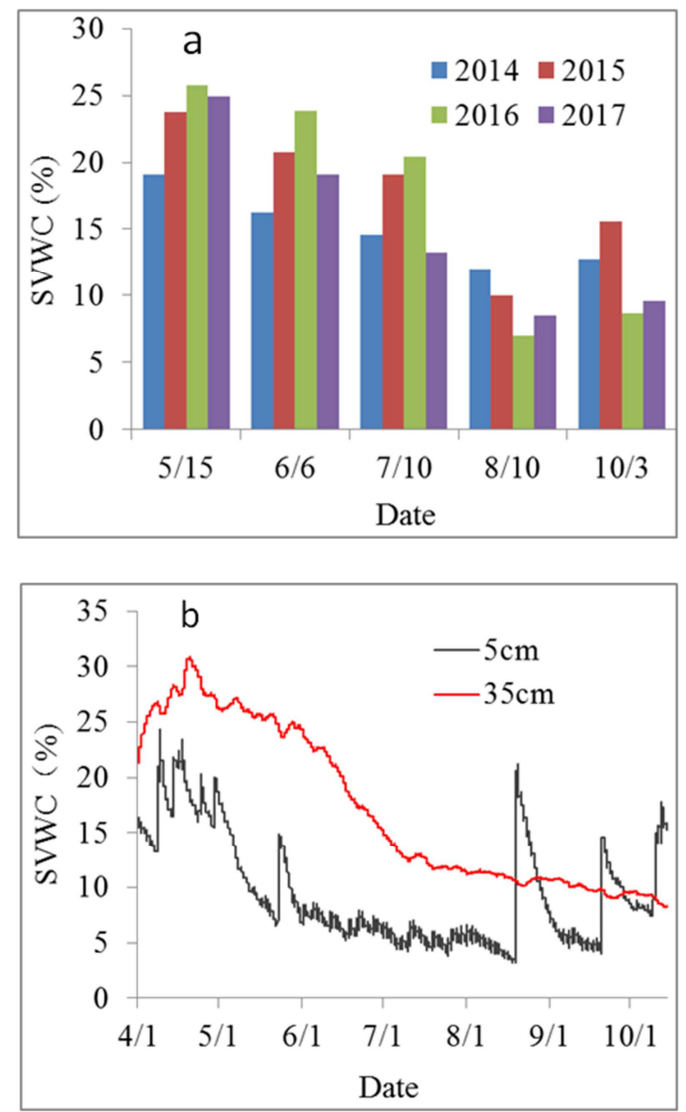

Figure 1. Comparison of the $0-40 \mathrm{~cm}$ soil volumetric water content (SVWC) for 2014 - 2017 (a) and the SVWC at different depths during the growing season of 2014 (b). 
Table 1. Temperature, precipitation, and aboveground biomass at the experimental site (a low-mountain dry grassland in the Tianshan Mountains) from 2014 to 2017.

\begin{tabular}{lllllllll}
\hline & & \multicolumn{2}{l}{ Growing stage } & & & \\
\cline { 3 - 8 } & & I & II & III & IV & V & VI & I-VI \\
\hline \multirow{2}{*}{2014} & Average daily temperature $\left({ }^{\circ} \mathrm{C}\right)$ & 7.75 & 12.81 & 16.40 & 19.65 & 19.27 & 12.20 & 14.00 \\
& Average daily precipitation $(\mathrm{mm})$ & 1.24 & 1.35 & 1.04 & 1.11 & 0.32 & 0.74 & 1.01 \\
& Average daily aboveground biomass $\left(\mathrm{mg} / \mathrm{m}^{2}\right)$ & 630.67 & 241.82 & 111.47 & 40.32 & 0 & 23.64 & 212.47 \\
& Average daily temperature $\left({ }^{\circ} \mathrm{C}\right)$ & 9.72 & 13.36 & 15.06 & 23.50 & 16.66 & 9.25 & 14.13 \\
\multirow{2}{*}{2015} & Average daily precipitation $(\mathrm{mm})$ & 1.31 & 3.81 & 2.57 & 0.65 & 4.63 & 1.21 & 2.08 \\
& Average daily aboveground biomass $\left(\mathrm{mg} / \mathrm{m}^{2}\right)$ & 702.22 & 357.73 & 100.59 & 23.55 & 0 & 5.15 & 235.43 \\
& Average daily temperature $\left({ }^{\circ} \mathrm{C}\right)$ & 9.00 & 13.54 & 17.74 & 18.89 & 19.01 & 15.99 & 15.10 \\
\multirow{2}{*}{2016} & Average daily precipitation $(\mathrm{mm})$ & 1.90 & 1.61 & 1.44 & 1.12 & 0 & 0.18 & 1.11 \\
& Average daily aboveground biomass $\left(\mathrm{mg} / \mathrm{m}^{2}\right)$ & 690.45 & 430.91 & 142.35 & 61.61 & 0 & 0 & 254.46 \\
& Average daily temperature $\left({ }^{\circ} \mathrm{C}\right)$ & 8.27 & 14.91 & 19.82 & 21.26 & 13.00 & 11.89 & 14.56 \\
& Average daily precipitation $(\mathrm{mm})$ & 1.64 & 0.99 & 1.65 & 0.39 & 0.90 & 0.52 & 1.06 \\
& Average daily aboveground biomass $\left(\mathrm{mg} / \mathrm{m}^{2}\right)$ & 638.22 & 433.64 & 52.06 & 0 & 0 & 0 & 215.22 \\
\hline
\end{tabular}

I: 1 April to 15 May, II: 16 May to 6 June, III: 7 June to 10 July, IV: 11 July to 10 August, V: 11 to 30 August, VI: 1 September to 3 October, I-VI: 1 April to 3 October.

From 1 April to 3 October, the $\mathrm{AB}$ was ranked from high to low, as follows: $2016>2015>2017>2014$ (Table 1). Plants were subject to water stress in the LMDG of the Tianshan Mountains. However, even though the highest precipitation occurred in 2015, AB was not the highest in this year. In 2015, abundant and high-intensity precipitation caused the amount of runoff to increase (Table 1 and Figure 2) [14]. Thus, available precipitation for plant growth decreased (Figure 1a). From 1 April to 6 June, inter-annual variation in $A B$ was similar to the recorded changes in temperature (Table 1). Heat, rather than water, was the limiting factor for plant growth, due to high SVWC caused by abundant snow melt water during this stage (Figure 1). Thus, $\mathrm{AB}$ was high in years with high temperature during this stage. This result contrasts with existing publications showing that heat is not the limiting factor for plant growth in this region [4]. Based on the observations, plants were green from 7 June to 10 July in 2014 - 2016. In contrast, plants began to wilt during this stage in 2017. Because the temperature was very high and the SVWC was relatively low during this stage in 2017, plants entered dormancy earlier (Table 1 and Figure 1a) [12]. From 11 July to 10 August, inter-annual variation in $\mathrm{AB}$ was similar to that of precipitation (Table 1). In this case, water, not heat, was the limiting factor for plant growth, because of the high temperature and low SVWC (Figure 1). Consequently, $\mathrm{AB}$ was high in years with high precipitation during this stage.
From 11 to 30 August, plants entered dormancy, due to the high temperature and low SVWC (Figure 1) [12]. Thus, the $\mathrm{AB}$ was zero during this stage (Table 1). From 1 September to 3 October of $2014-2015$, plants continued to grow slowly after dormancy. During this stage, precipitation was higher in 2015 than in 2014, while AB was lower in 2015 than in 2014. These differences might have been caused by the lower temperature in 2015 [15]. From 1 September to 3 October in 2016 - 2017, precipitation was low. In addition, one high-intensity precipitation event occurred during this stage in 2017, which led to more runoff and, therefore, less available precipitation for plant growth [14]. Thus, plants did not continue to grow during this stage in 2016 and 2017 (Table 1 and Figures 1 and 2).

This study is the first to investigate $\mathrm{AB}$ dynamics during the growing season in the LMDG of the Tianshan Mountains. And experimental observation represents the most precise methodology and approach for assessing grassland $\mathrm{AB}$ dynamics [9]. Therefore, the results are expected to provide new insights on $A B$ dynamics in the LMDG of the Tianshan Mountains, and to provide baseline data to enhance future grassland management. Of course the datasets collected by existing studies remain limited; thus, the implementation of further field-based studies in this region are encouraged to confirm the results and advance current knowledge.

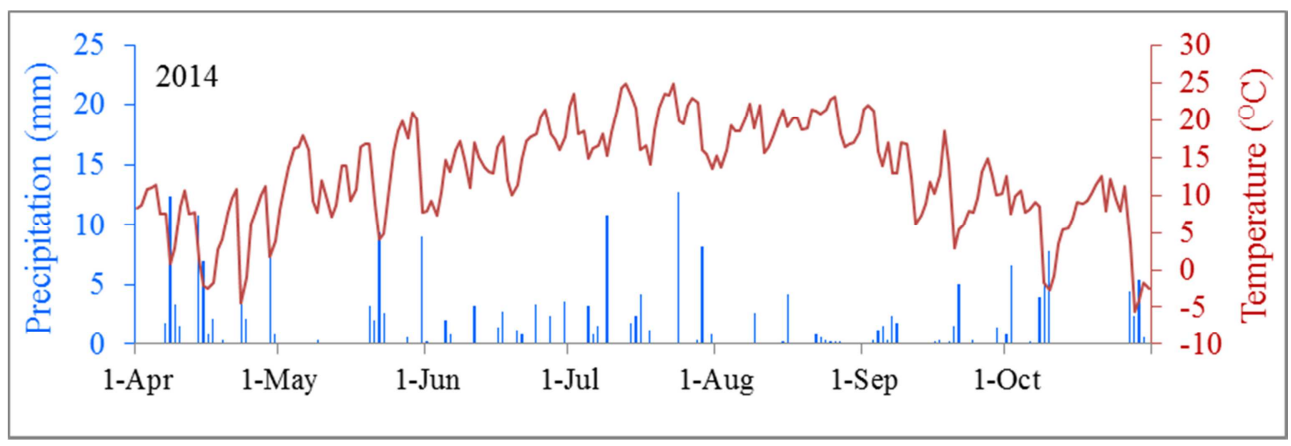



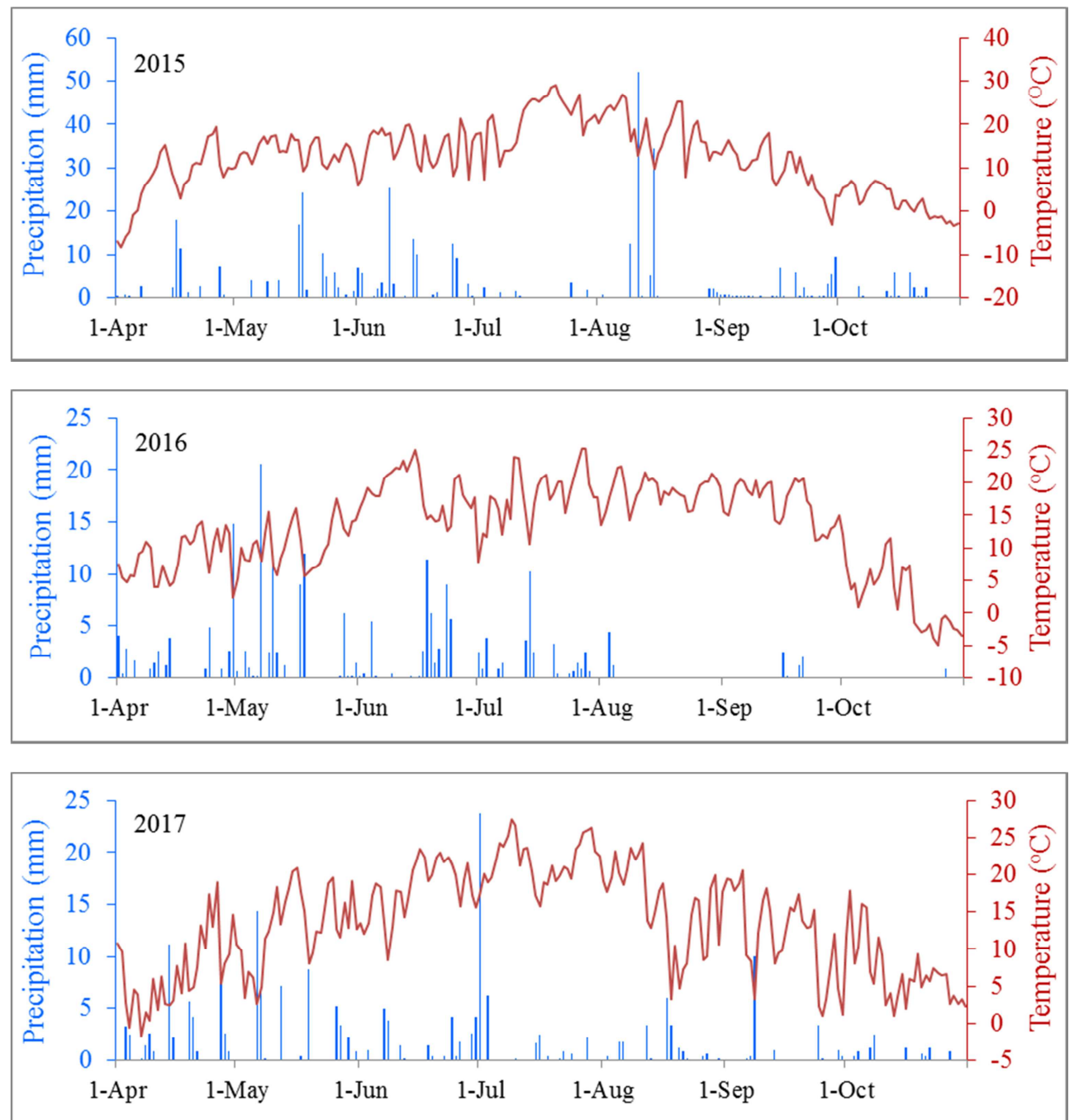

Figure 2. Daily temperature and precipitation in the low-mountain dry grassland (LMDG) near Fukang, Xinjiang, China from 2014 to 2017.

\section{Conclusion}

In this study, $\mathrm{AB}$ dynamics in the LMDG of the Tianshan Mountains were determined based on systematic observations from 2014 to 2017. AB dynamics had unique characteristics, because of the influence of the unique environment of this region. $\mathrm{AB}$ increased rapidly in spring (April - May) due to the high SVWC caused by snow melt water, and then increased slowly in summer (June - August) and autumn (September - October) mainly because of phenology and low SVWC. Plants entered dormancy in summer (primarily August) due to low SVWC and high air temperature. In autumn, plants continued to grow after dormancy, except in years with low precipitation which limited plant growth. Plants generally suffered from water stress in this region. However, in spring, the limiting factor for plant growth was heat, not water. Heat might also be the limiting factor for plant growth in autumn. The results are expected to enhance the understanding of $\mathrm{AB}$ dynamics in the LMDG of the Tianshan Mountains, providing data to support local grassland management.

\section{Author Contributions}

Xiaotao Huang and Geping Luo designed the study; Xiaotao Huang, Geping Luo, Hao Wang and Jean Baptiste Nsengiyumva collected the data; Xiaotao Huang analysed the data; Xiaotao Huang wrote the manuscript. All authors gave final approval for publication and agree to be accountable for all aspects of the work.

\section{Data Accessibility}

The datasets supporting this article have been uploaded as part of the supplementary material.

\section{Funding}

This research was supported by CAS "Light of West China" Program (2018) "The effect of grazing on grassland productivity in the basin of Qinghai Lake"; Key R\&D and Transformation Projects in Qinghai Province (2018-SF-146); and the Qinghai Innovation Platform Construction Project 
(2017-ZJ-Y20).

\section{Competing Interests}

We declare we have no competing interests.

\section{Ethical Statement}

All the data were collected by us through observations.

\section{Acknowledgements}

We thank Professor Y. R. Zheng for providing advice on the study.

\section{References}

[1] Liang W, Lu Y, Zhang W, Li S, Jin Z, Ciais P, et al. Grassland gross carbon dioxide uptake based on an improved model tree ensemble approach considering human interventions: global estimation and covariation with climate. Glob. Change Biol. 2017; 23: 2720-2742. doi: 10.1111/gcb.13592.

[2] Deqing H, Lan YU, Yaosheng Z, Xinquan Z. Above-ground biomass and its relationship to soil moisture of natural grassland in the northern slopes of the Qilian Mountains. Acta Pratacult. Sinica 2011; 20: 20-27.

[3] Li F, Zeng Y, Luo J, Ma R, Wu B. Modelling grassland aboveground biomass using a pure vegetation index. Ecol. Indic. 2016; 62: 279-288. doi: 10.1016/j.ecolind.2015.11.005.

[4] Luo G, Han Q, Zhou D, Li L, Chen X, Li Y, et al. Moderate grazing can promote aboveground primary production of grassland under water stress. Ecol. Complex 2012; 11: 126-136. doi: 10.1016/j.ecocom.2012.04.004.

[5] Xi N, Zhang C, Bloor JMG. Species richness alters spatial nutrient heterogeneity effects on above-ground plant biomass. Biol. Lett. 2017; 13. doi: 10.1098/rsbl.2017.0510.

[6] Zhang W, Zhang F, Qi J, Hou F. Modelling impacts of climate change and grazing effects on plant biomass and soil organic carbon in the Qinghai-Tibetan grasslands. Biogeosciences 2017; 14: 5455-5470. doi: 10.5194/bg-14-5455-2017.

[7] Huang X, Luo G, He H, Wang X, Amuti T. Ecological effects of grazing in the Northern Tianshan Mountains. Water 2017; 9: 932-950. doi: 10.3390/w9120932.

[8] Zhao WY, Li JL, Qi JG. Changes in vegetation diversity and structure in response to heavy grazing pressure in the northern Tianshan Mountains, China. J. Arid Environ. 2007; 68: 465-479. doi: 10.1016/j.jaridenv.2006.06.007.

[9] Wang K, Dickinson RE. A review of global terrestrial evapotranspiration: Observation, modelling, climatology, and climatic variability. Rev. Geophys. 2012; 50. doi: 10.1029/2011rg000373.

[10] Huang X, Luo G, Wang X. Land-atmosphere exchange of water and heat in the arid mountainous grasslands of Central Asia during the growing season. Water 2017; 9: 727. doi: $10.3390 /$ w9100727.

[11] Zhu J, Zhang Y, Wang W. Interactions between warming and soil moisture increase overlap in reproductive phenology among species in an alpine meadow. Biol. Lett. 2016; 12. doi: 10.1098/rsbl.2015.0749.

[12] Balachowski JA, Bristiel PM, Volaire FA. Summer dormancy, drought survival andfunctional resource acquisition strategies in California perennial grasses. Annals Bot. 2016; 118: 357-368. doi: 10.1093/aob/mcw109.

[13] Dlamini P, Chivenge P, Manson A, Chaplot V. Land degradation impact on soil organic carbon and nitrogen stocks of sub-tropical humid grasslands in South Africa. Geoderma 2014; 235: 372-381. doi: 10.1016/j.geoderma.2014.07.016.

[14] Arora VK, Chiew FHS, Grayson RB. Effect of sub-grid-scale variability of soil moisture and precipitation intensity on surface runoff and streamflow. J. Geophys. Res.-Atmos. 2001; 106: 17073-17091. doi: 10.1029/2001jd9000371.

[15] Singh A, Khurana P. Molecular and functional characterization of a wheat $\mathrm{B} 2$ protein imparting adverse temperature tolerance and influencing plant growth. Frontiers Plant Sci. 2016; 7: 642-661. doi: 10.3389/fpls.2016.00642. 